\title{
Identification OF Post-Combustion Sub-Process Using Artificial Neural Networks
}

\author{
Deynier Montero Góngora ${ }^{1 *}$, Ever Góngora Leyva ${ }^{2}$ and Mercedes Ramírez Mendoza ${ }^{3}$ \\ ${ }^{1}$ Master's Degree in Electro-Mechanics, Moa University, Cuba \\ ${ }^{2}$ PHD's Degree in Technical Science, Moa University, Cuba \\ ${ }^{3} P H D$ 's Degree in Technical Science, Universidad de Oriente, Cuba \\ *Corresponding author: Deynier Montero Góngora, Master's Degree in Electro-Mechanics; Moa University, Holguin, Cuba
}

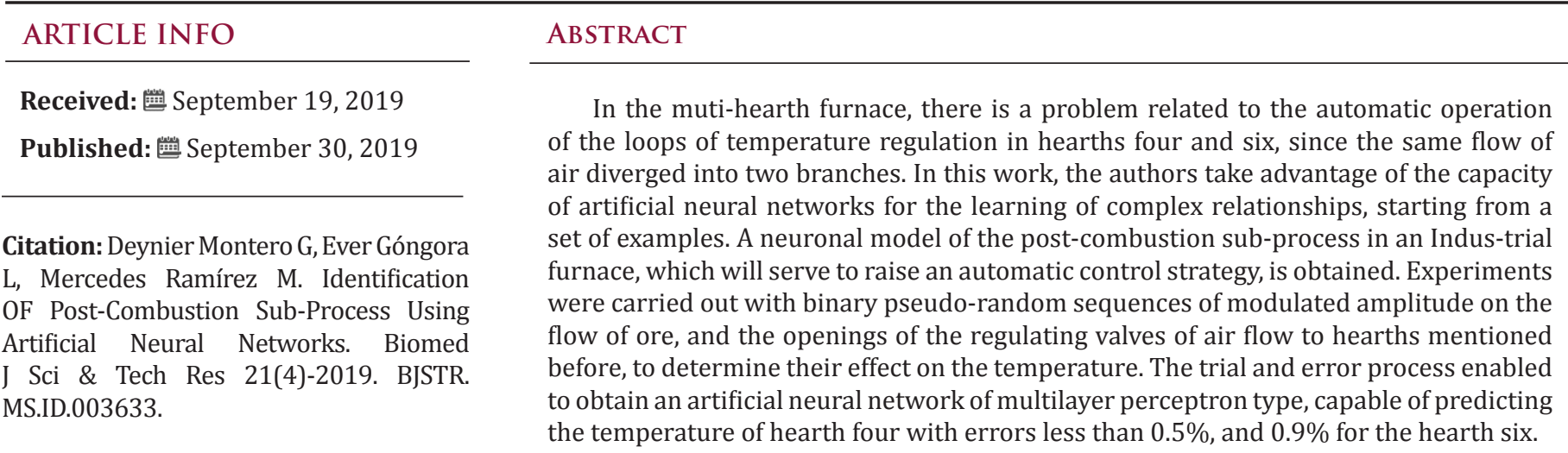

Keywords: Multi-Hearth Furnace; Artificial Neural Networks; Automatic Control; PostCombustion

\section{Introduction}

The Mining and Metallurgical Industry has become one of the bases of the economic-industrial development in Cuba. For this reason, it currently faces the challenge of Management Improvement to achieve a competitive industrial level worldwide. This Management improvement, as an integrated process, cannot ignore the technological improve-ment starting from a consistent application of advances in science and technology. In the nickel plants, in which the carbonate-ammonia leaching technology is used, also universally known as the "Caron" process, the multi-hearth furnaces [1] are used for mineral reduction. They represent an important link in the productive chain. The current work was carried out in one of these plants, specifically in the post-combustion sub-process of a reduction furnace, in which several automatic control strategies were previously used without success, attributed to the non-linear behavior of the temperature as a function of the steady-state post-combustion airflow [2]. A mathematical model that describes the dynamics of the process must be available to design an automatic control strategy that guarantees the existing demands [3]. Nowadays, there is a growing interest in neural networks due to its great versatility and to the continuous advance in network training algorithms as well as in hardware [4]. Taking into account the facts previously described, the objective of this research is to model the post combustion in the multi hearth furnace of a Nickel plant, by using artificial neural networks, for the future implementation of a control architecture to increase the energy efficiency of the process.

\section{Materials and Methods}

\section{The Process of Reduction}

The Herreshoff type furnaces [5] (Figure 1), are composed of

(i) A metal cylinder covered on the inside with refractory bricks, protected on the outside by a metal framework,

(ii) Installation for stirring, feeding and discharging of ore, and 
(iii) Combustion chambers. Inside the metal cylinder, there are 17 spherical vaults shaped hearths or screeds. In the center, there is a rotating shaft to which 68 arms are attached, 4 for each hearth (Figure 1).

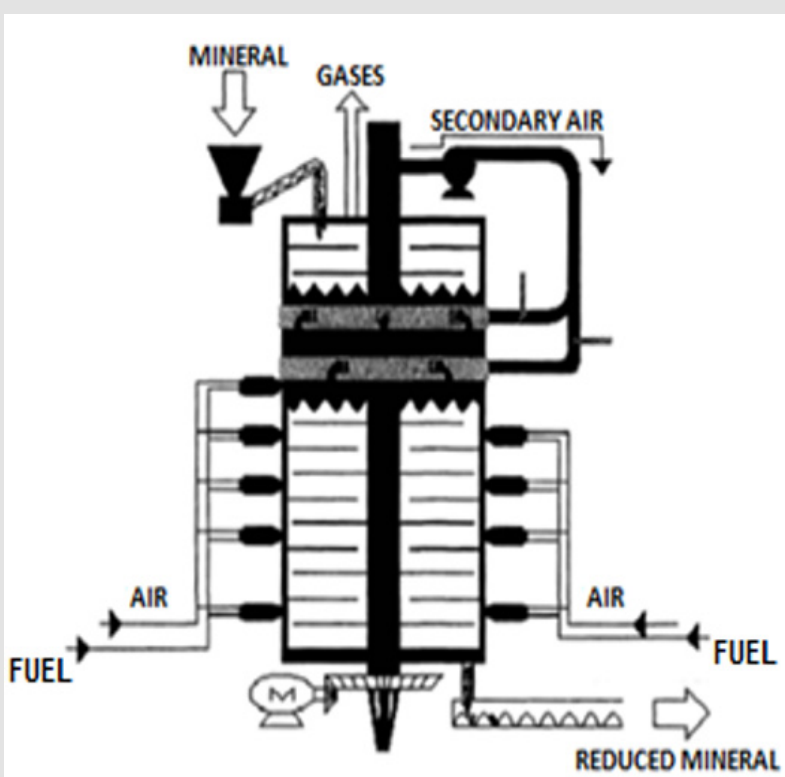

Figure 1: Hysteresis type characteristic deformation of piezo actuator.

After the ore is weighed, it is discharged to the auger feeder, which transports the ore to the hearth in the upper part of the furnace, in which the ore is retained during approximately 45 minutes. The reduction process is eminently endothermic. For this reason, the furnace has 10 combustion chambers located in hearths 15, 12, 10, 8 and 6 with high-pressure oil burners, which produce hot gases for heating the ore, while enriching the reducing atmosphere of the furnace, since they work with incomplete combustion. Thus, the ore in its descent is subjected to a rising temperature that allows a gradual heating, while the concentration of reducing gases i.e. carbon monoxide (CO) and hydrogen gas $\left(\mathrm{H}_{2}\right)$ increases. The concentration of these gases in contact with the ores at the beginning of decomposition is extremely important. After reducing the nickel oxide, the mineral mixture is discharged from the furnace to a rotating conveyor [6]. In hearths 4 and 6 of the furnace, secondary air is introduced by means of a fan (Figure 1), with the purpose of burning the $\mathrm{CO}$ and $\mathrm{H}_{2}$ not consumed in the previous reduction stages, according to the following equations:

$$
\begin{aligned}
& \mathrm{CO}+\frac{1}{2} \mathrm{O}_{2} \rightarrow \mathrm{CO}_{2}+6.76 \frac{\mathrm{Mkcal}}{\mathrm{kmal}} \\
& \mathrm{H}_{2}+\frac{1}{2} \mathrm{O}_{2} \rightarrow \mathrm{H}_{2} \mathrm{O}+57.8 \frac{\mathrm{Mkcal}}{\mathrm{kmal}}
\end{aligned}
$$

As can be seen from equation (1) and (2), these oxidation reactions are exothermic and provide part of the heat needed in the upper hearths ( 4 to 0 ). The combustion in hearths 4 and 6 also avoids that the concentration of $\mathrm{CO}$ and $\mathrm{H}_{2}$ in the gases that leave the furnace exceed the permissible emission limits, which would lead to environmental pollution. Furthermore, it increases the overall energy efficiency of the process.

\section{Obtaining an Approximate Model of the Process through Experimental Identification}

Obtaining a mathematical model that describes the process from the phenomenological point of view would be extremely complicated, since the physicochemical processes involved would lead to differential equations systems in partial derivatives, nonlinear and variable in time. Therefore, experimental identification was chosen $[7,8]$.

Notions of Modeling using Neural Networks: It has been shown that neural networks can be effectively and accurately used for the identification and control of systems with complex dynamics, especially for non-linear plants varying over time, and that are more difficult to regulate with conventional methods [9]. In real life, most industrial processes belong to this category, hence the need for intelligent methods to control those systems. Neural networks provide more accurate models than conventional methods, in the identification of some systems, especially for non-linear systems with variable parameters [4]. The multilayer perceptron network (or MLP), see Figure 2, is probably the most widely used type of network. The main reason for this selection is its ability to model, in a simple way, complex function-al relationships. This has been proved through numerous practical applications (Figure 2). The class of MLP network considered here has a single hidden layer with a hyperbolic tangent activation function (f) and in the output layer a linear activation function $(\mathrm{F})$ :

$\hat{y}_{t}=(w, W)=F_{i}\left(\sum_{j=1}^{q} w_{i j} h_{j}(w)+W_{i 0}\right)=F_{i}\left(\sum_{j=0}^{q} w_{i j} f_{j}\left(\sum_{i=1}^{m} w_{j l} z_{l}+w_{j 0}\right)+W_{i 0}\right)$

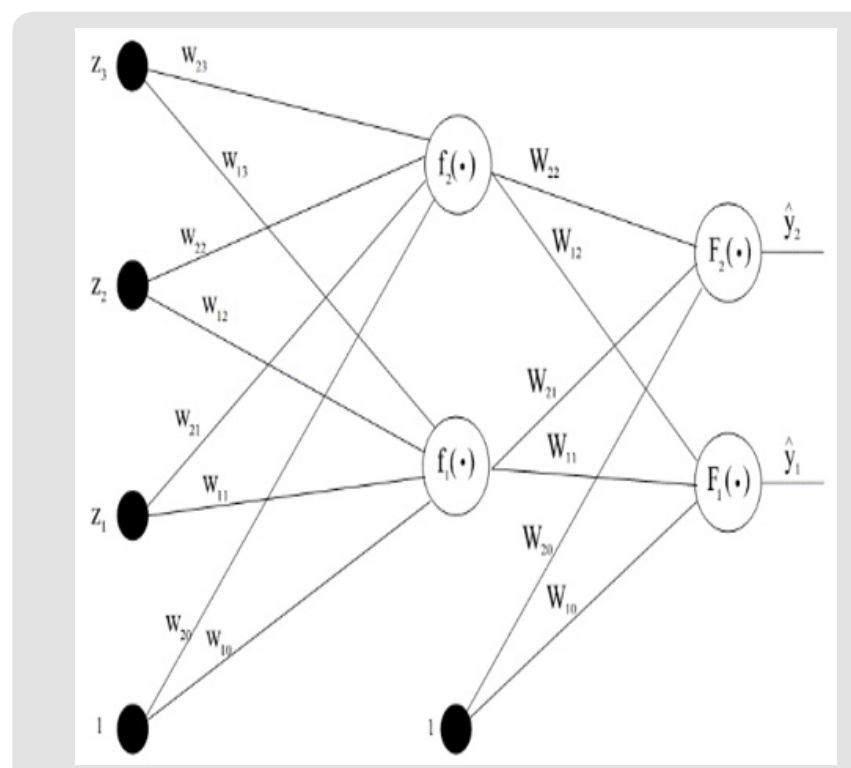

Figure 2: Multilayer perceptron network.

The weights (specified by the vector $\theta$ or alternatively by the matrices $w$ and $W$ are the adjustable parameters of the network and are determined starting from the set of examples during the 
training process. The examples, or training data, constitute the set of systems $u(t)$, and their corresponding outputs $y(t)$. The training set is given by:

$$
Z^{N}=\{[u(t), y(t)] \mid t=1, \ldots, N\}
$$

The identification can be seen as the determination of the mapping of the training data set, to the set of possible weights: $Z^{N} \rightarrow \hat{\theta}$ so that, the network can produce a prediction $\hat{y}(t)$ as close as possible to the actual output $y(t)$. A method of predicting error, which is the strategy applied here, is based on the introduction of a measure of proximity in terms of the least square's criterion.

$$
V_{N}\left(\theta, Z^{N}\right)=\frac{1}{2 N} \sum_{I=1}^{N}[y(t)-\hat{y}(t / \theta)]^{T} \ldots .[y(t)-\hat{y}(t / \theta)]
$$

The weights are calculated as:

$$
\hat{\theta}=\arg \min V_{N}\left(\theta, Z^{N}\right)
$$

Through some kind of iterative minimization scheme:

$$
\theta^{(i+1)}=\theta^{(i)}+\mu^{(i)}+f^{(i)}
$$

Where $\theta^{(i)}$ specifies the current iteration (number ' $i$ '), is the search direction, and $\mu^{(i)}$ the step.

As in any process of identification of a dynamic system, the four classic steps were followed: obtaining the input-output data, selecting the structure of the model, estimating the model and validating it. Regarding the selection of the structure of the model, it is not only necessary to select a set of regressors, but also the architecture of the network. The procedure used is described in [10]. The idea is to select the regressors based on the identification of linear systems and then determine the best possible network architecture with the regressors given as input. The LevenbergMarquardt was used as a training algorithm. The MATLAB ${ }^{\circledR}$ program and the identification toolbox with neural networks developed by M Nørgaard [10] were used as a software to carry out the research.

\section{Analysis of the Experiments Carried Out}

Several experiments using binary pseudo random sequences (APRBS) of order 5 to the input variables were applied, and multiple replicas were made in order to achieve an adequate longitude of the input signal. The sampling period was calculated in three seconds taking into account the dynamics of the process. Details on the conditions under which the trials were conducted can be found in [11]. The model based on artificial neural networks for the postcombustion sub-process of the ore reduction furnace is shown in Figure 3. The vertical sig-nals are also considered as inputs of the three models, but they vary in time (Figure 3).

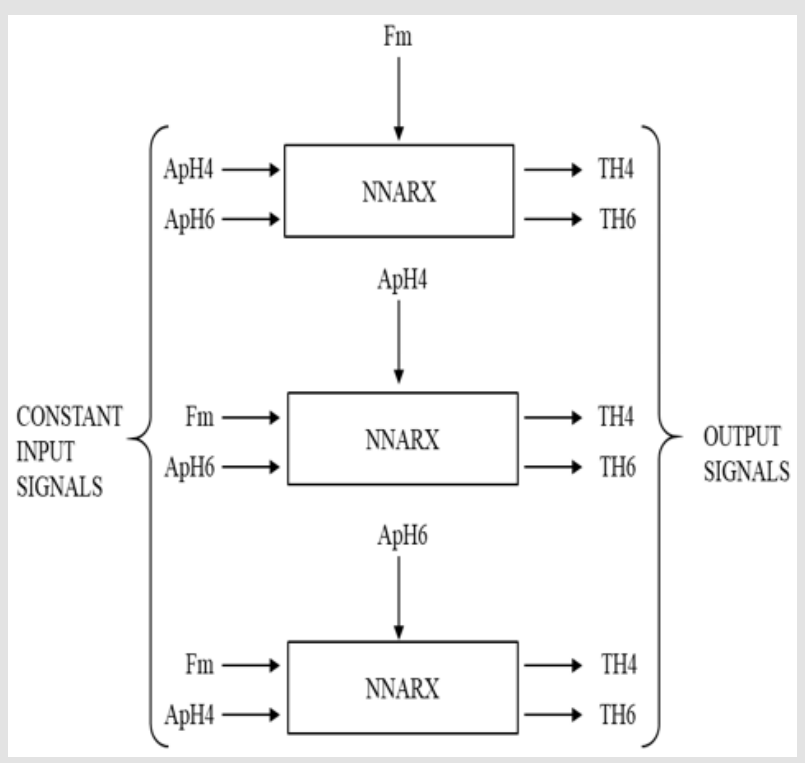

Figure 3: Structure of the general model of the three experiments.

Experiment 1: Variation of Air Flow in H4: During the experiment, 1240 data were taken corresponding to the variables TH4, TH6 and ApH4. In this case, the opening of the hearth four experienced a variation of 12 to $57 \%$ of its total distance, the opening of the valve of the six-hearth remained constant at $40 \%$ and the flow of ore fed to the furnace was $18.2 \mathrm{t} / \mathrm{h}$. In Figure 4 , the measurements of the input and output variables can be seen (Figure 4).

In this case, the non-linear autoregressive model (NNARX) was selected:

$$
\begin{aligned}
& \hat{y}(t / \theta)=\hat{y}(t / t-1, \theta)=g(\varphi(t), \theta) \\
& \varphi(t)=\left[y(t-1) \ldots y\left(t-n_{a}\right) u\left(t-n_{k}\right) \ldots u\left(t-n_{b}-n_{k}+1\right)\right]^{T}
\end{aligned}
$$

Specifically, a totally connected network architecture composed of five neurons, hyperbolic tangent in the hidden layer and a linear neuron as output, was taken. The results of the validation are shown in Figure 5, where prediction errors for TH4 are $0.5 \%$. For TH6 the validation tests showed the data ex-posed in Figure 6, with prediction errors of $0.09 \%$ (Figures 5 \& 6). 


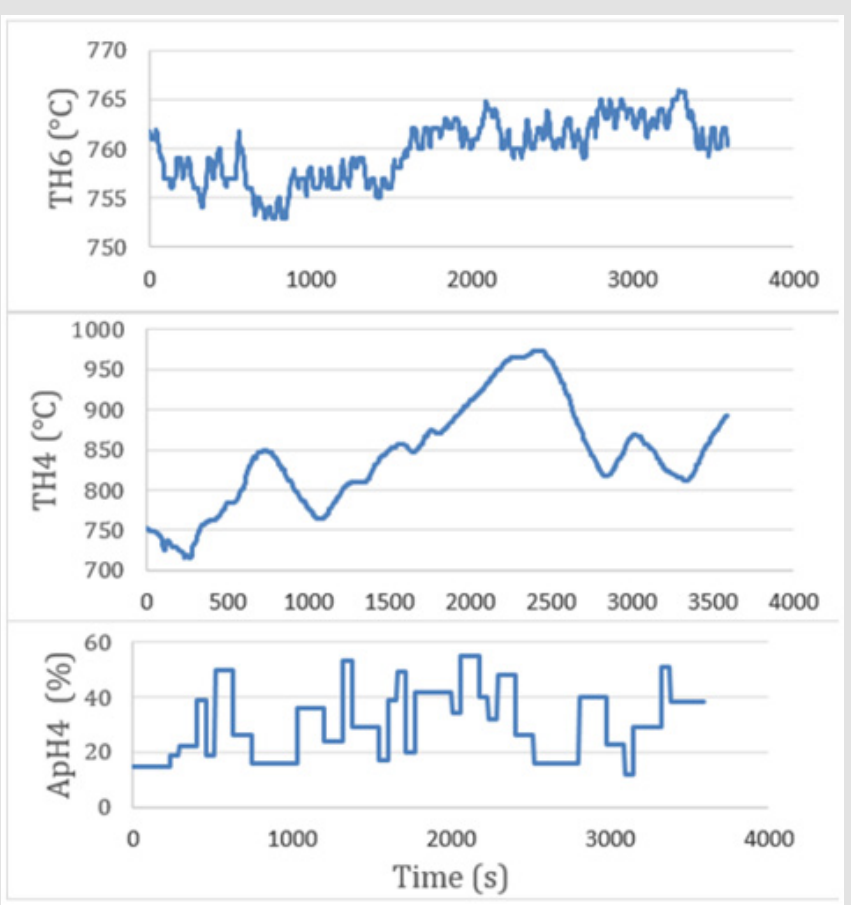

Figure 4: Variation of ApH4 (experiment 1).
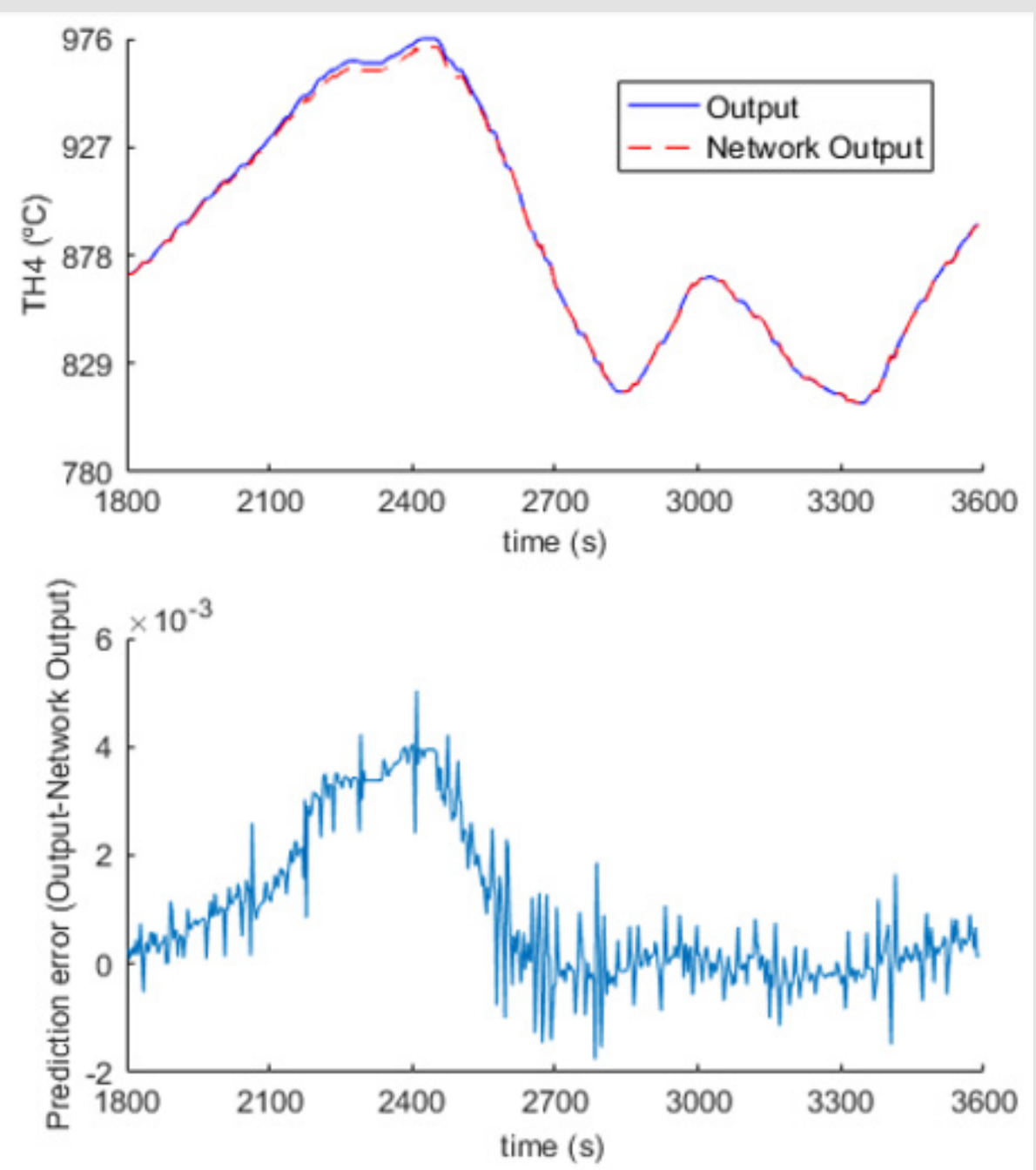

Figure 5: Network output vs. Actual output and error prediction for TH4. 

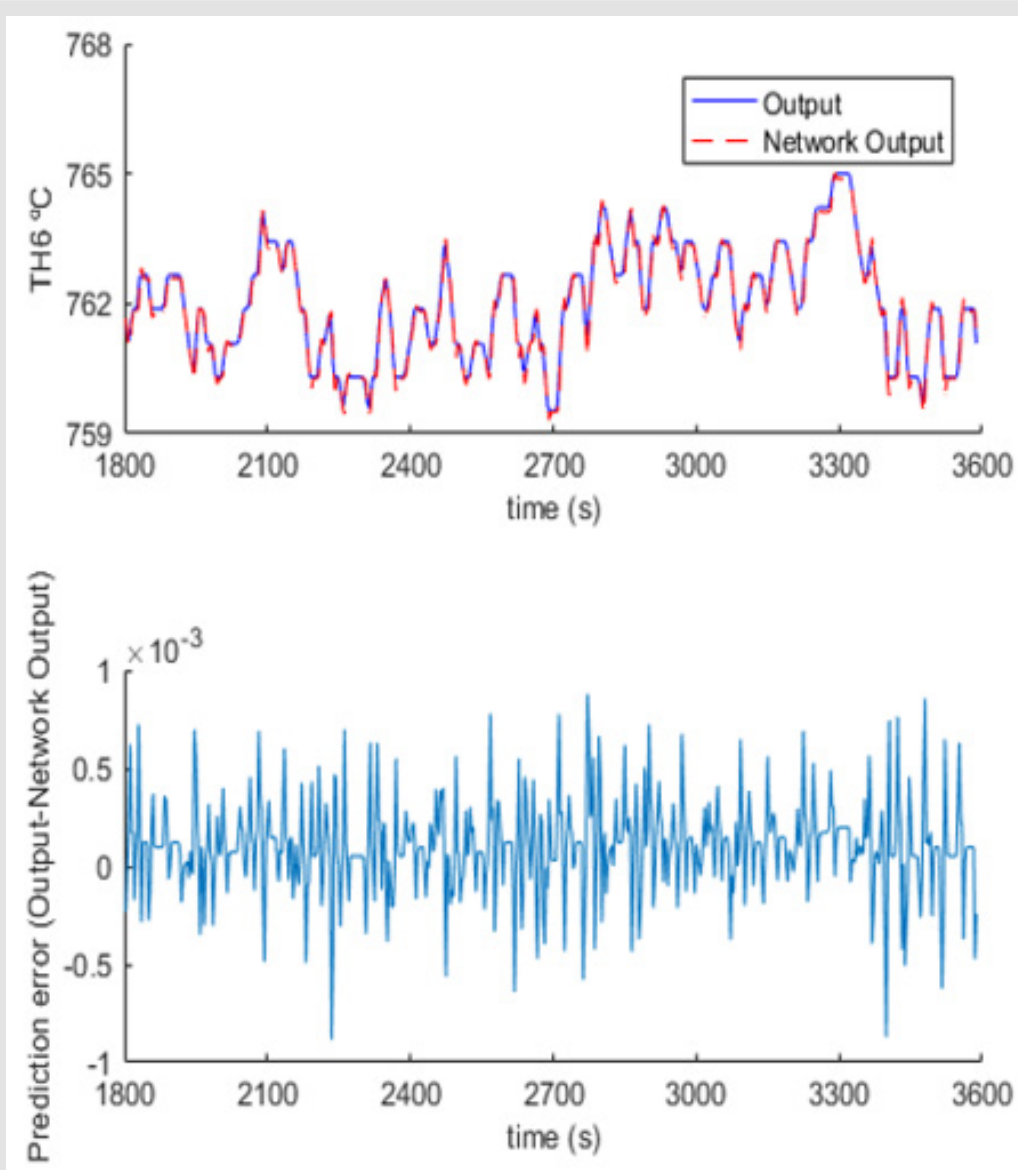

Figure 6: Network output vs. Actual output and error prediction for TH6.

Experiment 2: Variation of Air Flow in H6: During the experiment, 1240 data were taken corresponding to the variables TH4, TH6 and ApH6. In this case, the opening of home six experienced a variation of 20 to $68 \%$ of its total distance, while the opening of the valve of the hearth four was kept constant at $25 \%$, with a flow of ore fed to the furnace of $18.2 \mathrm{t} / \mathrm{h}$. Figure 7 shows the measurements of the input and output variables. After following the same procedure described for the first experiment, prediction errors of $0.3 \%$ are made for the hearth temperature six (Figure 8). Figure 9 shows the validation test for hearth temperature four, where prediction errors of $0.5 \%$ are made (Figures 7-9).

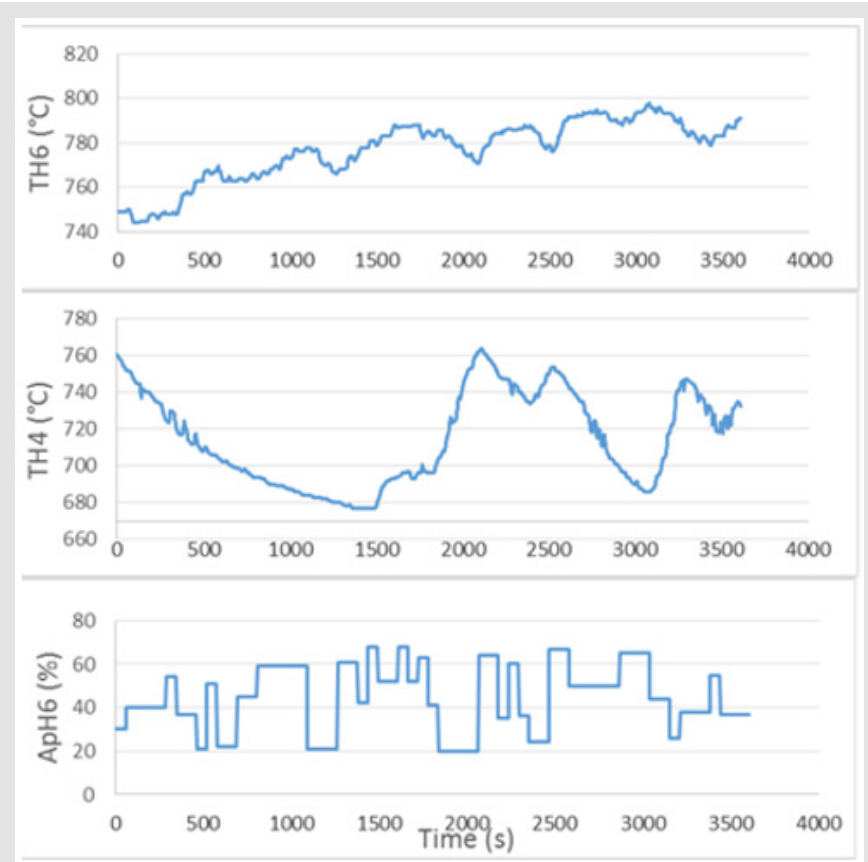

Figure 7: Variation of ApH6 (experiment 2). 

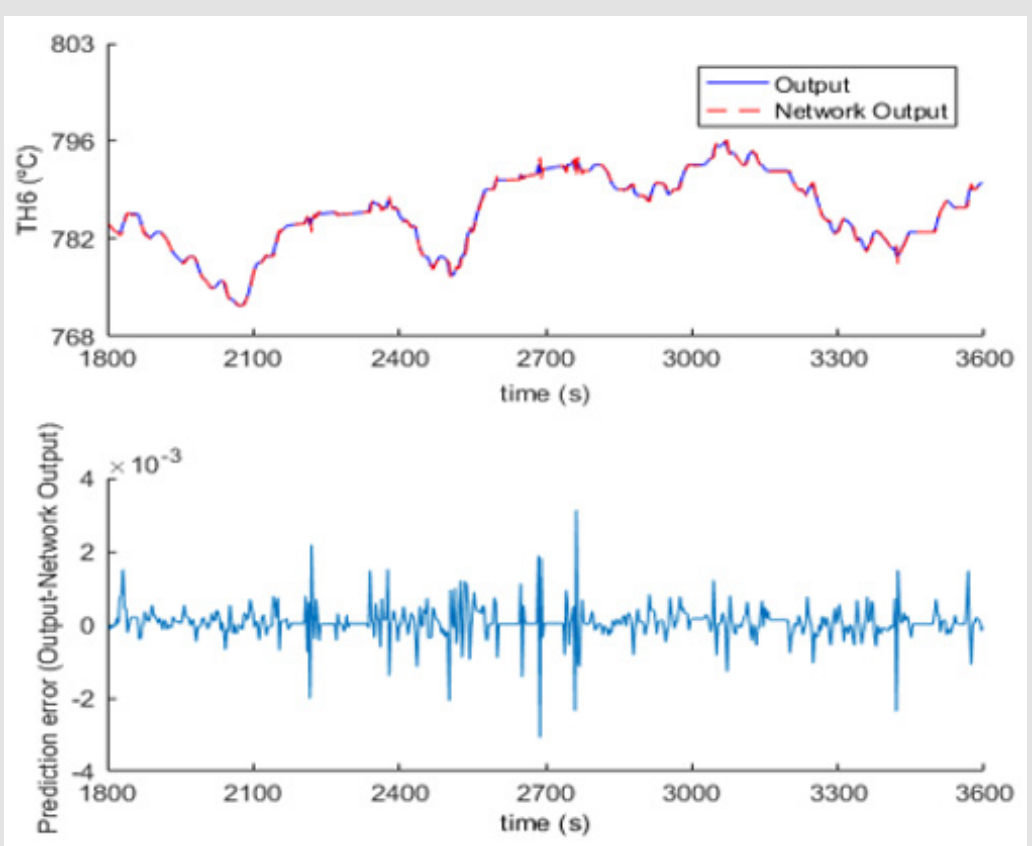

Figure 8: Network output vs. Actual output and error prediction for TH6.

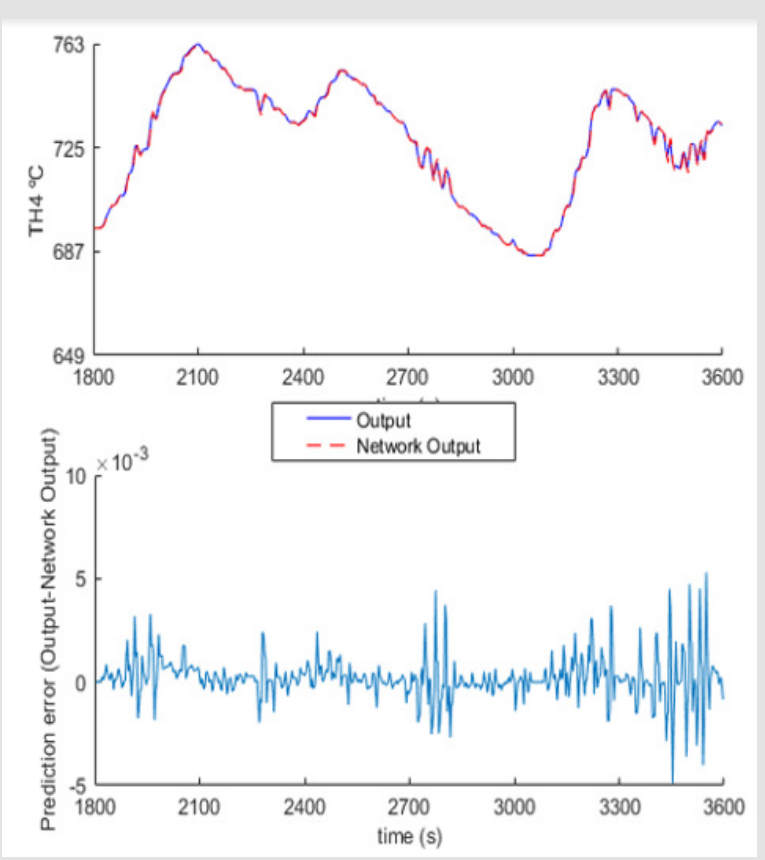

Figure 9: Network output vs. Actual output and error prediction for TH4.

Experiment 3: Variation of Mineral Flow: During the experiment, 1103 data were taken corresponding to the variables TH4, TH6 and Fm. Figure 10 shows the results of the input and output variables obtained after experimenting with ore flows of 16 to $19 \mathrm{t} / \mathrm{h}$, while the valve openings of hearths four and six were kept constant in 20 and $30 \%$, respectively (Figure 10). Figures $11 \& 12$ show the results during the validation for the observed outputs, where lower pre-diction errors are observed for the home temperature six with respect to the home temperature four (Figures 11 \& 12). The results of the comparison showed that the model obtained through the use of ANN, reflects with more accuracy the dynamic characteristics of the post-combustion sub-process than the linear models obtained in [7], thus, testing the potentialities that offers this tool of artificial intelligence. 

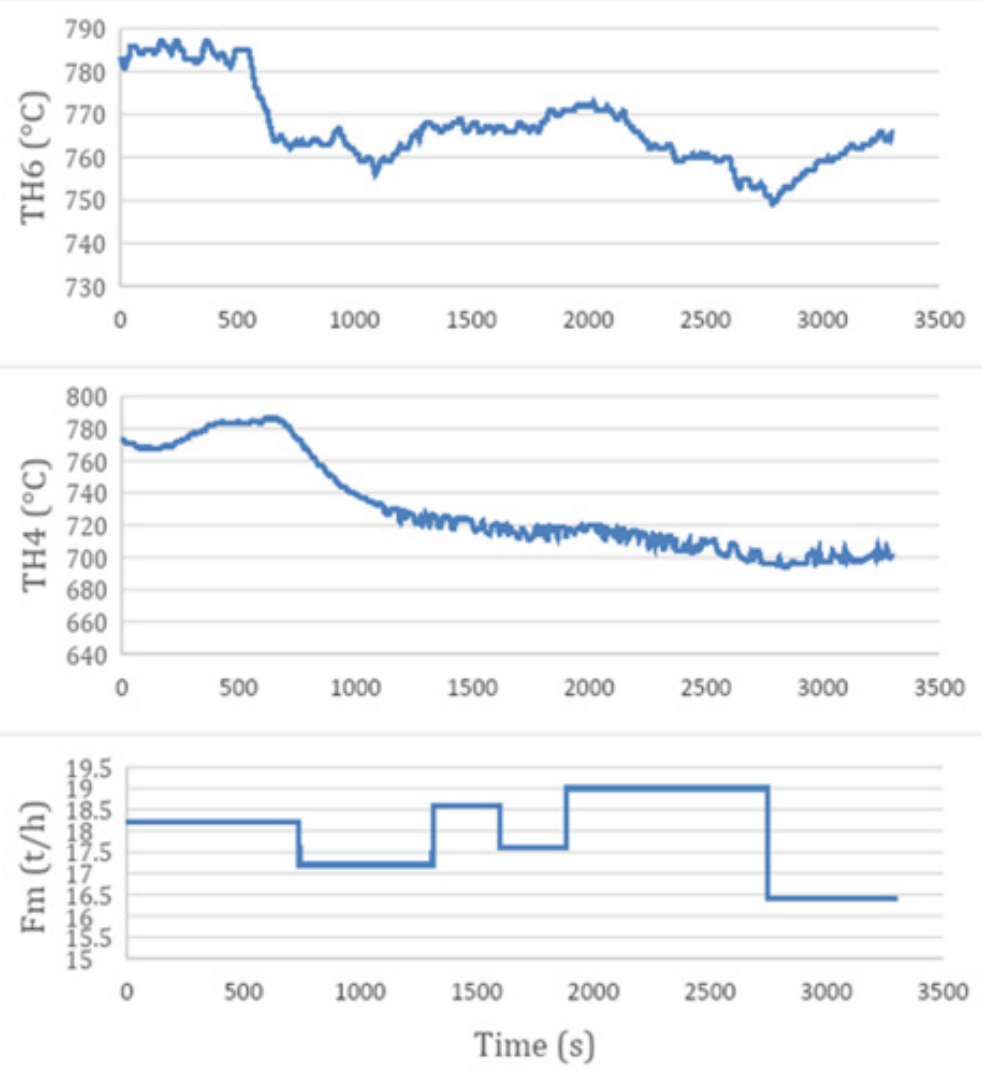

Figure 10: Variation of Fm with time (experiment 3).
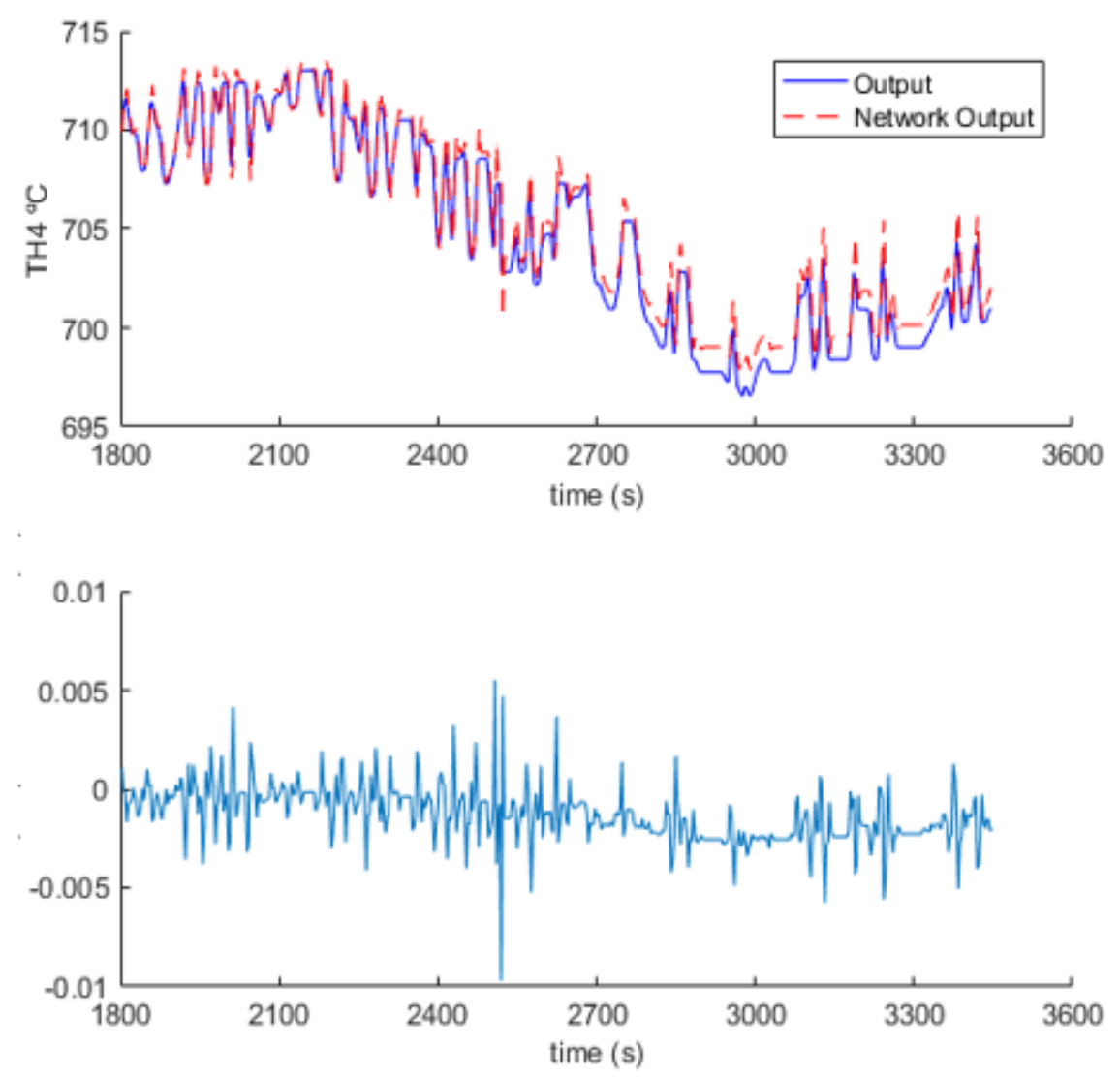

Figure 11: Network output vs. Actual output and error prediction for TH4. 

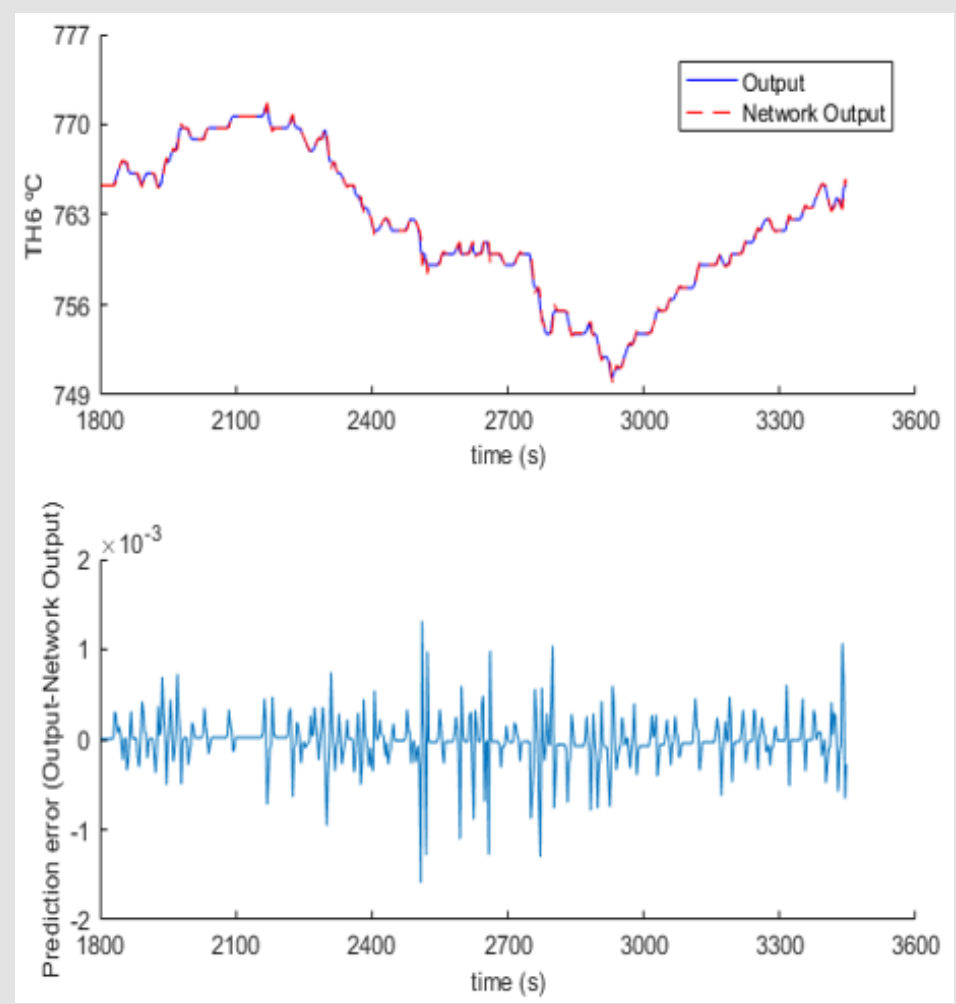

Figure 12: Network output vs. Actual output and error prediction for TH6.

\section{Conclusion}

Despite the significant effort made on the research about gassolid reactions that occur during material processing operations, the knowledge of such reactors is still essentially incomplete; particularly in the context of the reduction of laterites, to which the present study is linked. The artificial neural networks models of temperatures in hearths four and six before changes in their air flow, were obtained. These models were validated, providing superior adjustments to those achieved with the linear models.

\section{Acknowledgment}

To the master's degree in Higher Education Adelfa Verdecia Cruz for her valuable contribution in this paper's translation.

\section{References}

1. Castellanos J, Casto R, García I (1986) Elabo-ración de minerales oxidados de níquel por el esquema carbonato amoniacal. Minería \& Geología 4 (2): 77-91.

2. Ramírez M (2002) Control Borroso de la Post-combustión en un Horno de Múltiples Hoga-res, Tesis de doctorado, Instituto Superior Politécnico José Antonio Echeverría, Ciudad de La Habana.

3. Caldas O, Jiménez S, Mejía E, Hernán dez J, Avilés O (2012) Identificación paramétrica en lazo cerrado de sistema de accionamien-to neumático para cilindro de doble efecto. Revista Facultad de Ingeniería UPTC 21(33): 9-19.

4. Santos M (2011) Un Enfoque Aplicado del Con-trol Inteligente. RIAI 8(4): 283-296.

5. Habashi F (1997) Handbook of Extractive Metal-lurgy, Wiley-VCH, Weinheim, Germany. 2(3).

6. (2007) Manual de operaciones de la Planta Hornos de Reducción de la empresa. Comandante Ernesto Ché Guevara de Moa.

7. Montero D, Ramírez M, Gilbert A, Perdi ces S (2015) Modelación matemática para el con-trol de la postcombustión en un horno de reducción de níquel. RIELAC 36(3): 21-34.

8. Ramírez M (2002) Modelado del proceso de postcombustión en un horno de reducción de níquel. Revista de Metalurgia, España 38(2): 150157.

9. Ricardo Valverde Gil, Diego Gachet Páez (2007) Identificación de sistemas dinámicos utilizando redes neuro-nales RBF. RIAI 4(2): 32-42.

10. Nørgaard M (2000) Neural Network Based System Identification Toolbox, Report. 00-E-891, Department of Automation, Technical University of Denmark.

11. Montero D (2018) Modelación de la postcombus-tión en un horno de múltiples hogares utili-zando redes neuronales artificiales, Tesis de Maestría, ISMMM, Moa, 2016. Editorial Digi-tal Universitaria de Moa, consulta 22 de fe-brero de. 


\section{ISSN: 2574-1241}

DOI: 10.26717/BJSTR.2019.21.003633

Deynier Montero Góngora. Biomed J Sci \& Tech Res

(C) (P) This work is licensed under Creative BY Commons Attribution 4.0 License

Submission Link: https://biomedres.us/submit-manuscript.php

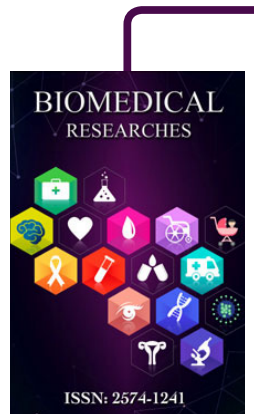

Assets of Publishing with us

- Global archiving of articles

- Immediate, unrestricted online access

- Rigorous Peer Review Process

- Authors Retain Copyrights

- Unique DOI for all articles

https://biomedres.us/ 